\title{
Perancangan Skenario Adaptif untuk Reward pada Gamifikasi Reseller Penjualan Daring menggunakan Finite State Machine
}

\author{
Diny Syarifah Sany ${ }^{1}$, Fauzan Zikri ${ }^{2}$ \\ Program Studi Teknik Informatika ${ }^{1}$, Administrasi Bisnis Internasional ${ }^{2}$ \\ Universitas Suryakancana \\ dsy.sany@gmail.com ${ }^{1}$,fauzanzikri8@gmail.com
}

\begin{abstract}
The increase in online buyers makes online sales increase. To increase sales, apart from promoting to various platforms, sellers also recruit resellers. Resellers are an important element in online sales in terms of increasing sales, promotion, and brand building. Good communication with resellers is the key to online business cooperation. Another study states that the use of gamified rewards in online sales can increase employee productivity, one of which is resellers. This study discusses the design of gamification reward adaptive scenarios for resellers using the Finite State Machine method. The designed scenario will result in different rewards for resellers. The final result of this research is an adaptive scenario model for rewards that can be applied to the gamification of reseller data collection applications for online sales.
\end{abstract}

Keywords: Adaptive Scenario, Gamification, Reward, Reseller, Online Sales, Finite State Machine

\begin{abstract}
Abstrak
Kenaikan pembeli daring membuat penjualan daring menjadi meningkat. Untuk menaikkan penjualan selain melakukan promosi ke berbagai platform penjual juga merekrut reseller. Reseller menjadi elemen penting pada penjualan daring dalam hal meningkatkan penjualan, promosi, serta membangun merek. Komunikasi yang baik dengan reseller menjadi kunci dalam kerjasama bisnis daring. Penelitian lain menyatakan bahwa penggunaan reward gamifikasi pada penjualan daring dapat meningkatkan produktivitas karyawan salah satunya adalah reseller. Penelitian ini membahas mengenai perancangan skenario adaptif reward gamifikasi untuk reseller dengan menggunakan metode Finite State Machine. Skenario yang dirancang akan menghasilkan reward yang berbeda terhadap reseller. Hasil akhir dari penelitian ini adalah model skenario adaptif untuk reward yang dapat diterapkan pada gamifikasi aplikasi pendataan reseller untuk penjualan daring.
\end{abstract}

Kata Kunci : Skenario Adaptif, Gamifikasi, Reward, Reseller, Penjualan Daring, Finite State Machine

\section{PENDAHULUAN}

Perangkat bergerak kini sudah menjadi kebutuhan harian masyarakat dunia. Kegiatan-kegiatan konvensional sekarang sudah mulai berubah menjadi kegiatan daring. Bisnis daring atau daring sudah mulai bersaing penuh dengan bisnis konvensional. Perkembangan bisnis daring paling pesat terletak pada penjualan daring baik yang dilakukan di aplikasi khusus seperti e-commerce atau melalui sosial media. Pengaruh reseller sangat penting sebagai media pengembangan penjualan daring. Secara tidak langsung reseller menjadi media promosi secara gratis untuk penjual pertama. Keberadaan penting dari reseller inilah yang akan mempengaruhi naik turunnya laba penjual pertama. Penjual perlu memiliki komunikasi yang baik dengan reseller. Penjual harus dapat mampu membangun produktivitas dan kesetiaan reseller-nya.

Gamifikasi juga membuka paradigma baru didalam berbagai sektor kehidupan. Elemen-elemen game yang diadaptasi ke sektor non game akan membuat sektor tersebut menjadi lebih meningkat kualitasnya. Penggunaan gamifikasi akan menghapus sistem yang terlalu formal sehingga sektor tersebut menjadi lebih bersemangat untuk meningkatkan produktifitasnya. Sektor-sektor yang dapat diterapkan gamifikasi salah satunya adalah bisnis misalnya penjualan daring. Penerapan gamifikasi pada penjualan daring meningkatkan kepuasan pelanggan, produktivitas karyawan, meningkatkan laba dan merek dagang [1]. Penggunaan gamifikasi dalam penjualan daring dapat memotivasi reseller dalam menaikkan penjualan salah satunya dengan pemberian reward atau hadiah atas capaian yang telah diperolehnya.

Finite State Machine sendiri merupakan metode komputasi yang memiliki status akhir diterma atau ditolak. Hasil akhir finite state machine ini akan dipengaruhi oleh input yang diberikan. Model skenario adaptif dengan finite state machine dapat digunakan 
untuk menentukan reward apa yang sesuai diberikan kepada reseller sesuai dengan hasil penjualan reseller tersebut.

Penelitian ini bertujuan untuk merancang model skenario adaptif reward yang dapat diterapkan pada gamifikasi aplikasi reseller yang dapat memberikan pengalaman berbeda kepada reseller nya sesuai dengan penjualan bulanannya.

\section{METODE PENELITIAN}

Metode yang digunakan dalam perancangan skenario adaptif ini adalah dengan menggabungkan konsep reward, gamifikasi pada penjualan daring, dan finite state machine untuk memodelkan perilaku.

\subsection{Gamifikasi pada penjualan daring}

Gamifikasi adalah penggunaan elemen game dan teknik desain game dalam konteks non-game, seperti kesehatan, pendidikan, politik, sektor publik, dan bisnis[1]. Aturan dasar yang harus dimiliki saat akan membuat gamifikasi pada bisnis daring :

a. Jangan memaksa pengguna untuk melakukan tugas yang meningkatkan upaya untuk melakukan pembelian.

b. Jangan pernah merusak citra produk atau toko

c. Kelola target yang menarik bagi pengguna dalam jangka pendek, menengah, dan Panjang

d. Kelola gamifikasi ke pelanggan toko yang paling umum

Secara keseluruhan, gamifikasi meningkatkan keterlibatan pengguna. Namun, ada perbedaan mencolok antara jenis penghargaan individu. Pengguna dengan imbalan berwujud 4,1 kali lebih aktif daripada pengguna dengan imbalan tidak berwujud. Imbalan nyata meningkatkan aktivitas pengguna secara keseluruhan dan peningkatan yang diamati tidak terlalu terdistorsi oleh beberapa pengguna super aktif [2].

\subsection{Reward}

Reward merupakan kompensasi finansial atau nonfinansial yang diberikan kepada karyawan sebagai bentuk imbalan atas tenaga kerja atau layanan yang diberikan di tempat kerja [3]. Reward dapat digunakan untuk mengelola dan memotivasi orang dengan memahami secara menyeluruh signifikansi relatif yang ditempatkan pada berbagai aspek proposisi hadiah dan menerapkan strategi total hadiah yang dirancang dengan baik secara efektif [4]. Reward digunakan untuk memotivasi karyawan untuk bekerja lebih baik, dan juga untuk mempertahankan karyawan. Agar sistem reward menjadi motivasi yang ideal, reward harus memenuhi berbagai kriteria: memiliki nilai, cukup besar untuk berdampak, dapat dimengerti, tepat waktu, efeknya harus tahan lama dan akhirnya penghargaan harus hemat biaya[3]. Jenis reward pun berbeda dan dapat disesuaikan dengan tujuan akhir yang ingin dicapai.

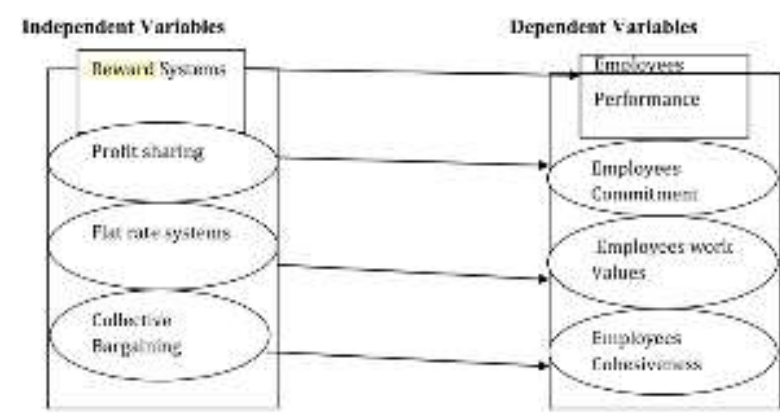

Gambar 1 Reward Framework pada Bisnis[5]

Bagi hasil memiliki pengaruh positif secara signifikan terhadap komitmen karyawan. Sistem flat rate memiliki pengaruh positif terhadap nilai kerja karyawan. Sistem penghargaan kelompok memiliki dampak positif yang signifikan terhadap kekompakan karyawan [5].

\subsection{Finite State Machine}

Finite State Machine adalah model perilaku dari sebuah sistem yang memiliki beberapa kondisi yang terdefinisikan dimana mode transisi akan berubah sesuai dengan keadaan yang diinputkan. Berikut adalah elemen utama dari sebuah finite state machine [6]:

a. State yang mendefinisikan perilaku mesin mungkin akan dapat menghasilkan aksi.

b. Transisi state adalah perpindahan dari satu state ke state lain.

c. Aturan atau kondisi yang harus dipenuhi supaya ada transisi state kejadian (events).

d. Input yang terjadi baik internal maupun external, yang memungkinkan trigger aturan dan mengacu ke transisi state.

Ada beberapa tahapan yang dapat dilakukan dalam membuat finite state machine. Tahap pertama dapat dilakukan dengan mendefinisikan perilaku yang ada, dan menggambarkan perilaku tersebut sebagai state. Tahap selanjutnya adalah menentukan transisi antar state dan kondisinya. Dan tahapan terakhir adalah menggabungkan semua state dan transisi [7].

\section{HASIL PENELITIAN}

Dalam penelitian ini maka ada jenis reward yang akan di skenariokan, yaitu flat rate system dan hadiah berupa barang/uang. Hal ini dikarenakan oleh hasil dari pengumpulan data terhadap 8 penjual pertama bahwa mereka cenderung bekerja sendiri tanpa berhubungan dengan reseller lainnya.

Tabel $1:$ Reward yang diberikan pada reseller

\begin{tabular}{|c|c|c|}
\hline Koresponden & $\begin{array}{c}\text { Jumlah } \\
\text { Reseller }\end{array}$ & \multicolumn{1}{c|}{ Reward } \\
\hline Koresponden 1 & 6 & $\begin{array}{c}\text { - Flat rate system } \\
\text { dengan minimal } \\
\text { pembelian } \\
- \text { Reward tahunan }\end{array}$ \\
\hline Koresponden 2 & 30 & $\begin{array}{c}\text { - Flat rate system } \\
\text { dengan minimal } \\
\text { pembelian } \\
\text { - Hadiah uang untuk } \\
\text { reseller terbanyak }\end{array}$ \\
\hline
\end{tabular}




\begin{tabular}{|c|c|c|}
\hline Koresponden & $\begin{array}{l}\text { Jumlah } \\
\text { Reseller }\end{array}$ & Reward \\
\hline & & $\begin{array}{l}\text { order dari segi jumlah } \\
\text { uang } \\
\text { - Reward tahunan }\end{array}$ \\
\hline Koresponden 3 & 15 & $\begin{array}{l}\text { - Flat rate system } \\
\text { dengan minimal } \\
\text { pembelian } \\
\text { - Reward tahunan }\end{array}$ \\
\hline Koresponden 4 & 4 & $\begin{array}{l}\text { - Flat rate system } \\
\text { dengan minimal } \\
\text { pembelian } \\
\text { - Reward tahunan }\end{array}$ \\
\hline Koresponden 5 & 43 & $\begin{array}{l}\text { - Flat rate system } \\
\text { dengan minimal } \\
\text { pembelian } \\
\text { - Hadiah uang untuk } \\
\text { reseller } \\
\text { teraktif/terbanyak dari } \\
\text { segi jumlah order } \\
\text { - Reward tahunan }\end{array}$ \\
\hline Koresponden 6 & 60 & $\begin{array}{l}\text { - Flat rate system } \\
\text { dengan minimal } \\
\text { pembelian } \\
\text { - Hadiah uang untuk } \\
\text { reseller terbanyak } \\
\text { order dari segi jumlah } \\
\text { uang } \\
\text { - Reward tahunan }\end{array}$ \\
\hline Koresponden 7 & 50 & $\begin{array}{l}\text { - Flat rate system } \\
\text { dengan minimal } \\
\text { pembelian } \\
\text { - Hadiah uang untuk } 3 \\
\text { reseller terbanyak } \\
\text { penjualan } \\
\text { - Reward tahunan } \\
\end{array}$ \\
\hline Koresponden 8 & 25 & $\begin{array}{l}\text { - Flat rate system } \\
\text { dengan minimal } \\
\text { pembelian } \\
\text { - Hadiah uang untuk } \\
\text { reseller terbanyak } \\
\text { order dari segi jumlah } \\
\text { uang } \\
\text { - Reward tahunan }\end{array}$ \\
\hline
\end{tabular}

Para koresponden pun mengatakan bahwa setelah melakukan pemberian reward reseller menjadi lebih aktif dan lebih semangat dalam berjualan sehingga penjualan mereka menjadi meningkat.

Setelah melakukan pengumpulan data dari 8 koresponden, scenario adaptif pada penelitian ini menghasilkan reward yang sesuai dengan input reseller. Berikut ini adalah elemen-elemen yang akan diadaptasi sesuai dengan metode yang sudah dianalisis pada poin sebelumnya.

\section{a. State}

State disini merupakan reward apa yang akan didapatkan oleh reseller. Dari hasil penelitian, reward yang didapatkan terdiri dari flat system rate dengan minimal pembelian, reward tahunan, reward untuk penjualan terbanyak dari segi jumlah order, dan reward terbanyak dari segi uang. Flat system rate yang dilakukan adalah dengan melakukan pemotongan harga atau penyesuaian harga menjadi lebih murah.

b. Transisi

Transisi atau perpindahan state ini dilakukan jika ada input yang sesuai untuk berpindah state.

c. Aturan

Adapun aturan yang berlaku pada finite state machine ini adalah sebagai berikut:

- Menjadi reseller aktif pertahun tersebut dengan melakukan minimal 1 order per bulan akan mendapatkan reward tahunan

- Menjadi reseller teraktif dengan penjualan terbanyak dari segi kuantitas barang akan mendapatkan reward reseller teraktif perbulan

- Menjadi reseller dengan penjualan terbanyak dari segi jumlah laba barang akan mendapatkan reward top reseller perbulan

- Mendapatkan flat system rate yaitu potongan harga dengan melakukan minimal order.

d. Input

Input yang diberikan adalah jumlah order dan jumlah laba dari reseller

Berikut ini scenario adaptif yang dihasilkan untuk reward gamifikasi yang dapat diterapkan pada pencatatan reseller dengan menggunakan metode Finite State Machine:

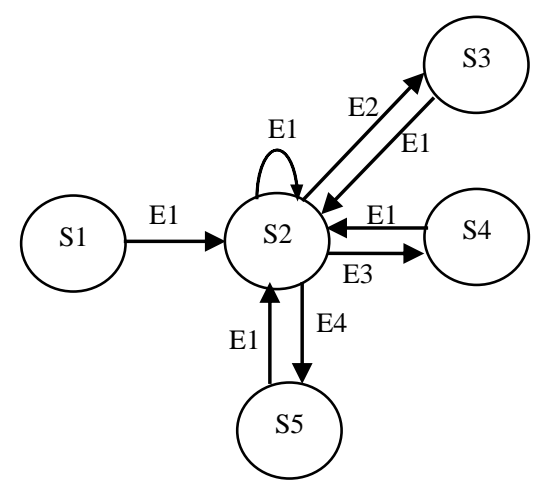

Gambar 2 Finite State Machine Skenario Adaptif Reward Gamifikasi Pendataan Reseller

State awal dari finite state machine ini adalah $\mathrm{S} 1$, penjelasan finite state machine tersebut dapat dilihat pada:

Tabel 2 Tabel Transisi Finite State Machine Skenario Adaptif Reward Gamifikasi Pendataan Reseller

\begin{tabular}{|c|c|c|c|c|}
\hline & E1 & E2 & E3 & E4 \\
\hline S1 & S1 & - & - & - \\
\hline S2 & S2 & S3 & S4 & S5 \\
\hline S3 & S2 & - & - & - \\
\hline S4 & S2 & - & - & - \\
\hline S5 & S2 & - & - & - \\
\hline
\end{tabular}

Keterangan

$\mathrm{S} 1$ : state reseller idle atau kondisi reseller tidak dapat reward

$\mathrm{S} 2$ : state reward tahunan

$\mathrm{S} 3$ : state reward reseller teraktif

$\mathrm{S} 4$ : state reward top reseller 
Diny Syarifah Sany ${ }^{1}$, Fauzan Zikri², Perancangan Skenario Adaptif untuk Reward pada Gamifikasi Reseller Penjualan Daring menggunakan Finite State Machine

S5 : state flat system rate

$\mathrm{E} 1$ : order minimal $1 \mathrm{x}$ perbulan

E2 : order terbanyak

E3 : pemasukan terbanyak

E4 : minimal order terpenuhi

Dalam setiap event atau transisi akan dilakukan pengecekan. Berikut ini adalah algoritma pengecekan event :

Transisi E1 : order minimal 1x perbulan

\section{Input(order)}

\section{If order then}

If thisMonthorder != lastMonthorder then

$$
\text { monthorderCount }+=1
$$

endif endif

if monthorderCount $==12$ then

resselerActive $=$ true

Transisi E2 : order terbanyak

\section{Input(order)}

monthlyorder $+=$ order

if monthlyorder > biggestMonthlyorder then

endif

$$
\text { resselerTopbyQuantity }=\text { true }
$$

Transisi E3 : pemasukan terbanyak

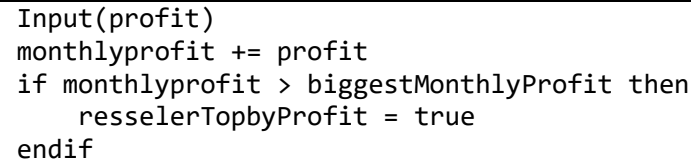

Transisi E4 : minimal order terpenuhi

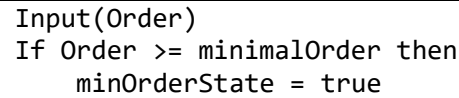

\section{PEMBAHASAN}

Dari skenario yang dibuat tidak semua reseller akan mendapatkan reward. Hanya reseller yang memenuhi kriteria saja yang akan mendapatkan reward. Reward pertama adalah reward tahunan. Reward ini akan diberikan kepada reseller yang aktif dengan minimal melakukan order sebanyak 1 kali selama satu bulan, sehingga diakumulasikan dia melakukan order selama 12 bulan. Selanjutnya adalah reward top reseller, reward ini akan diberikan kepada reseller yang memberikan profit terbesar kepada penjual, tidak melihat jumlah order. Reward ketiga adalah reward reseller terbanyak, order akan diakumulasikan dari segi jumlah barang tanpa melihat jumlah profit dan akan diperbaharui ulang setiap bulannya. Sedangkan untuk reward flat rate system akan diberikan jika minimal ordernya terpenuhi.

Uji coba dilakukan dengan membangun aplikasi pendataan reseller. Aplikasi pendataan reseller yang dibangun berbasis android. Aplikasi ini hanya menentukan reward apa yang didapatkan oleh reseller dan hanya sebatas pemberitahuan kepada penjual pertama saja. Input dilakukan dengan menambahkan di menu edit. Menu akun berfungsi untuk mencatat aturan yang diberlakukan, yaitu mengenai minimal order. Berikut adalah hasil implementasinya:

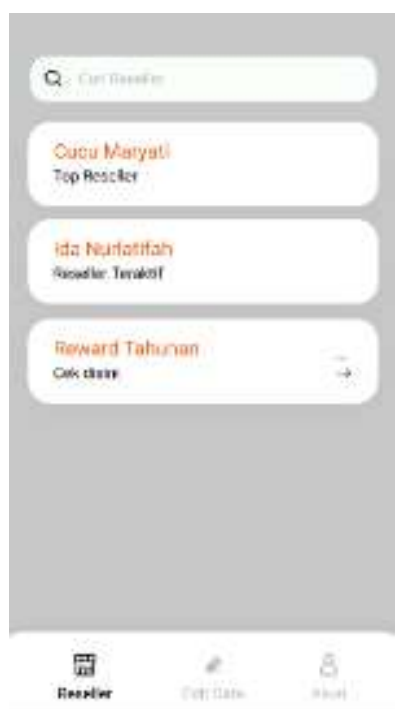

Gambar 3 Implementasi Skenario Adaptif

Data untuk skenario pengujian adalah sebagai berikut:

Tabel 3 : Jumlah order per-reseller

\begin{tabular}{|c|c|c|c|c|c|c|c|c|c|c|c|c|}
\hline \multirow{2}{*}{$\begin{array}{c}\text { Re } \\
\text { se } \\
\text { ler }\end{array}$} & \multicolumn{10}{|c|}{ Bulan } \\
\cline { 2 - 15 } & 1 & 2 & 3 & 4 & 5 & 6 & 7 & 8 & 9 & 10 & 11 & 12 \\
\hline A & 20 & 16 & 25 & 15 & 18 & 12 & 15 & 30 & 15 & 15 & 23 & 16 \\
\hline B & 10 & 21 & 18 & 16 & 16 & 19 & 14 & 10 & 10 & 11 & 21 & 22 \\
\hline C & 14 & 18 & 9 & 8 & 14 & 14 & 18 & 17 & 14 & 13 & 9 & 8 \\
\hline D & 13 & 24 & 27 & 12 & 27 & 15 & 16 & 14 & 11 & 26 & 30 & 21 \\
\hline E & 0 & 0 & 0 & 0 & 0 & 0 & 0 & 0 & 0 & 1 & 2 & 1 \\
\hline
\end{tabular}

Tabel 4 : Jumlah pemasukan dari reseller 1:Rp 10000

\begin{tabular}{|c|c|c|c|c|c|c|c|c|c|c|c|c|}
\hline \multirow{2}{*}{$\begin{array}{c}\text { Re } \\
\text { se } \\
\text { ler }\end{array}$} & \multicolumn{10}{|c|}{ Bulan } \\
\cline { 2 - 15 } & 1 & 2 & 3 & 4 & 5 & 6 & 7 & 8 & 9 & 10 & 11 & 12 \\
\hline A & 120 & 96 & 150 & 90 & 108 & 72 & 90 & 180 & 90 & 90 & 145 & 96 \\
\hline B & 60 & 156 & 108 & 96 & 96 & 100 & 84 & 60 & 60 & 66 & 126 & 120 \\
\hline C & 84 & 108 & 54 & 48 & 84 & 84 & 108 & 102 & 84 & 78 & 54 & 48 \\
\hline D & 78 & 144 & 162 & 72 & 162 & 110 & 96 & 84 & 66 & 156 & 140 & 126 \\
\hline E & 0 & 0 & 0 & 0 & 0 & 0 & 0 & 0 & 0 & 6 & 12 & 6 \\
\hline
\end{tabular}

*minimal order adalah untuk pembelian 1.000.000 (100 dalam skala 1:10000)

\begin{tabular}{|c|c|c|c|c|c|}
\hline Bulan & $\mathrm{A}$ & $\mathrm{B}$ & $\mathrm{C}$ & $\mathrm{D}$ & $E$ \\
\hline 1 & S2;S3;S4;S5 & S2; & S2; & S2; & S1; \\
\hline 2 & $\mathrm{~S} 2 ;$ & S2;S4;S5; & S2;S5; & S2;S3;S4;S5 & $\mathrm{S} 1$; \\
\hline 3 & S2;S5; & S2;S5; & S2; & S2;S3;S4;S5 & $\mathrm{S} 1$; \\
\hline 4 & S2; & S2;S3;S4; & $\mathrm{S} 2$ & $\mathrm{~S} 2$ & $\mathrm{~S} 1$; \\
\hline 5 & S2;S5; & $\mathrm{S} 2$ & S2; & S2;S3;S4;S5 & $\mathrm{S} 1$; \\
\hline 6 & S2; & S2;S3;S5; & S2; & $\mathrm{S} 2 ; \mathrm{S} 4 ; \mathrm{S} 5 ;$ & $\mathrm{S} 1$; \\
\hline 7 & $\mathrm{~S} 2$ & $\mathrm{~S} 2$ & S2;S3;S4;S5 & $\mathrm{S} 2$ & S1; \\
\hline 8 & $\mathrm{~S} 2 ; \mathrm{S} 3 ; \mathrm{S} 4 ; \mathrm{S} 5$ & S2; & $\mathrm{S} 2 ; \mathrm{S} 5 ;$ & S2; & $\mathrm{S} 1$; \\
\hline 9 & S2;S3;S4;S5 & S2; & $\mathrm{S} 2 ;$ & $\mathrm{S} 2 ;$ & $\mathrm{S} 1$; \\
\hline 10 & $\mathrm{~S} 2$ & S2; & $\mathrm{S} 2$ & S2;S3;S4;S5 & S2; \\
\hline 11 & $\mathrm{~S} 2 ; \mathrm{S} 4 ; \mathrm{S} 5 ;$ & S2;S5; & S2; & S2;S3;S5; & S2; \\
\hline 12 & $\mathrm{~S} 2$ & $\mathrm{~S} 2 ; \mathrm{S} 3 ; \mathrm{S} 5 ;$ & S2; & S2;S4;S5; & S2; \\
\hline
\end{tabular}

Dari skenario tersebut maka didapatkan hasil: 
Dari skenario diatas didapat bahwa:

- Reseller A mendapatkan reward tahunan, reward reseller teraktif dalam 3 bulan (bulan 1,8,9), reward top seller dalam 4 bulan (bulan 1, 8, 9, 11), dan flat system rate reward dalam 6 bulan (bulan 1, 3, 5, 8, 9, 11)

- Reseller B mendapatkan reward tahunan, reward reseller teraktif dalam 3 bulan (bulan 4, 6, 12), reward top seller dalam 1 bulan (bulan 2, 4), dan flat system rate reward dalam 5 bulan (bulan 2, 3, $6,11,12$ )

- $\quad$ Reseller C mendapatkan reward tahunan, reward reseller teraktif dalam 1 bulan (bulan 7), reward top seller dalam 1 bulan (bulan 7), dan flat system rate reward dalam 6 bulan (bulan 2, 7, 8)

- Reseller D mendapatkan reward tahunan, reward reseller teraktif dalam 5 bulan (bulan 2, 3, 5, 10, 11), reward top seller dalam 6 bulan (bulan 2, 3, 5, $6,10,12)$, dan flat system rate reward dalam 7 bulan (bulan 2, 3, 5, 6, 10, 11, 12)

- Reseller E hanya dipertimbangkan mendapatkan reward tahunan namun karena dalam algortima harus 12 bulan.

Selain menggunakan skenario tersebut, pengujian kesesuaian pun di lakukan kepada koresponden sebelumnya. Table hasil kuisioner dapat dilihat pada tabel berikut

\begin{tabular}{|c|c|c|c|c|c|c|c|c|c|}
\hline & K1 & K2 & K3 & K4 & K5 & K6 & K7 & K8 & $\begin{array}{c}\text { Rata- } \\
\text { rata }\end{array}$ \\
\hline P1 & 4 & 4 & 4 & 4 & 5 & 4 & 3 & 4 & 4 \\
\hline P2 & 3 & 4 & 4 & 4 & 5 & 4 & 4 & 5 & 4.1 \\
\hline P3 & 4 & 4 & 5 & 5 & 4 & 4 & 4 & 5 & 4.3 \\
\hline P4 & 4 & 4 & 4 & 4 & 5 & 5 & 4 & 5 & 4.3 \\
\hline
\end{tabular}

Nilai dari 1-5 : 1=tidak baik; 2=kurang; 3=cukup; 4=baik; 5=sangat baik;

Keterangan:

K1-K8 : koresponden 1 sampai 8

P1 : kesesuaian reward

P2 : mudah digunakan

P3 : mudah dipahami

P4 : membantu menentukan reward

Dari hasil pengujian tersebut dapat dikatakan bahwa skenario adaptif yang disarankan pada penelitian ini baik dan dapat dikatakan sesuai untuk reward pada gamifikasi pendataan reseller pada penjualan daring.

\section{KESIMPULAN}

Rancangan skenario adaptif reward gamifikasi untuk pencatatan reseller ini didasarkan pada hasil Analisa dari koresponden dan penelitian sebelumnya mengenai reward dalam penjualan. Model skenario ini dibuat untuk memudahkan pengembang jika akan membuat gamifikasi untuk reseller. Sehingga reward dapat diberikan secara berbeda sesuai dengan performa dari reseller. Selain itu skenario ini dapat memperlihatkan kinerja dari masing-masing reseller sehingga jika akan membuat level pada reseller atau reseller prioritas menjadi lebih mudah. Untuk implementasi aplikasi ini hanya mencatat pemasukan dari reseller saja sehingga di pengembangan selanjutnya diharapkan dapat membuat aplikasi reseller dengan sistem yang lengkap seperti barang yang tersedia, pembukuan transaksi dengan reseller, dan sebagainya. Kekurangan dari skenario ini adalah jika reseller tidak memiliki order dalam 1 bulan, namun sangat aktif di bulan lainnya maka dia tidak mendapatkan reward tahunan. Sehingga pada penelitian selanjutnya perlu adanya sistem kecerdasan untuk menentukan reward tahunan.

\section{REFERENSI}

[1] S. Hansun, "Gamified e-Commerce A New Paradigm on e-Media Business," J. Ultim., vol. 4, no. 2, pp. 28-31, 2012, doi: 10.31937/ti.v4i2.317.

[2] F. Huseynov, "Gamification in E-Commerce," IGI Glob., no. May, pp. 144-161, 2020, doi: 10.4018/978-1-7998-5171-4.ch008.

[3] U. Kingdom, J. S. Anku, M. Studies, B. K. Amewugah, M. Studies, and M. K. Glover, "Concept of Reward Management , Reward," Int. J. Econ. Commer. Manag., vol. VI, no. 2, pp. 621-637, 2018, [Online]. Available: http://ijecm.co.uk/.

[4] O. T. San, Y. M. Theen, and T. B. Heng, "The Reward Strategy and Performance Measurement ( Evidence from Malaysian Insurance Companies )," Int. J. Business, Humanit. Technol., vol. 2, no. 1, pp. 211-223, 2012.

[5] W. T. Ngwa, B. S. Adeleke, E. K. Agbaeze, N. C. Ghasi, and B. O. Imhanrenialena, "Effect of reward system on employee performance among selected manufacturing firms in the litoral region of Cameroon," Acad. Strateg. Manag. J., vol. 18, no. 3, pp. 1-16, 2019.

[6] M. B. Nendya, S. Gandang, R. G. Santosa, J. T. Elekto, and F. T. Industri, "Pemetaan Perilaku Non-Playable Character Pada Permainan Berbasis Role Playing Game Menggunakan Metode Finite State Machine Pendahuluan Game merupakan salah satu tipe animasi interaktif yang membuat player dapat Game merupakan sebuah jenis aktivitas bermai," J. Animat. Games Stud., vol. 1, no. 2, pp. 185-202, 2015.

[7] H. Haryanto, S. Novianto, and U. Rosyidah, "Model Skenario Adaptif Berbasis Finite State Machine Pada Game Pendidikan," Techno.COM, vol. 13, no. 2, pp. 91-98, 2014. 